San Jose State University

SJSU ScholarWorks

Faculty Publications

Electrical Engineering

2000

\title{
On the Error Performance of 8-VSB TCM Decoder for ATSC Terrestrial Broadcasting of Digital Television
}

Dojun Rhee

LSI Logic Corporation

Robert H. Morelos-Zaragoza

SONY Computer Science Laboratories, Inc., robert.morelos-zaragoza@sjsu.edu

Follow this and additional works at: https://scholarworks.sjsu.edu/ee_pub

Part of the Electrical and Computer Engineering Commons

\section{Recommended Citation}

Dojun Rhee and Robert H. Morelos-Zaragoza. "On the Error Performance of 8-VSB TCM Decoder for ATSC Terrestrial Broadcasting of Digital Television" Faculty Publications (2000)-218.

This Article is brought to you for free and open access by the Electrical Engineering at SJSU ScholarWorks. It has been accepted for inclusion in Faculty Publications by an authorized administrator of SJSU ScholarWorks. For more information, please contact scholarworks@sjsu.edu. 


\section{On the Error Performance of 8-VSB TCM Decoder for ATSC Terrestrial Broadcasting of Digital Television}

\author{
Dojun Rhee ${ }^{1}$ \\ LSI Logic Corporation \\ e-mail: drheelsil.com
}

\begin{abstract}
The error performance of various 8-VSB TCM decoders for reception of terrestrial digital television is analyzed. In previous work, 8-state TCM decoders were proposed and implemented for terrestrial broadcasting of digital television. In this paper, the performance of a 16-state TCM decoder is analyzed and simulated. It is shown that not only a 16-state TCM decoder outperforms one with 8-states, but it also has much smaller error coefficients.
\end{abstract}

\section{INTRODUCTION}

The Digital Television standard [1,2] describes a broadcasting system designed to transmit high quality video and audio as well aas data over a single $6 \mathrm{MHz}$ channel. In order to maximize service area, the terrestrial broadcast mode incorporate both an NTSC rejection filter (in the receiver) and trellis coding. When the NTSC rejection filter is activated in the receiver, a trellis decoder for the combination of a fourstate trellis encoder and the filter is used. In the paper, the error performance of various TCM decoders is studied, with and without the NTSC rejection (1-D) filter. In the previous results $[1,2]$, a combined 8-state trellis decoder is employed for the case with NTSC rejection filter. We propose a 16-state TCM decoder and analyze and simulate its error performance. The results show that the error performance improves, with respect to 8-state TCM decoders, at the cost of doubling the memory requirements. In return, a 16-state TCM decoder has much smaller error coefficients and does not require precoding to operate.

\section{ENCODER MODEL FOR ATSC TERRESTRIAL BROADCASTING OF DIGITAL TELEVISION}

In the ATSC terrestrial broadcasting system specification, the 8-VSB transmission subsystem employs a rate-2/3 4-state Ungerboeck trellis code, with the uncoded bit precoded. The 4-state feedback encoder and the bits-to- 8 PAM symbol mapper are shown in Fig. 1 (a). The NTSC interference rejection (comb) filter is a one tap linear-feed-forward (1-D) filter. Its purpose is to reduce the analog NTSC interference that is caused by a carrier tone. However, the received signals are also modified. The 8 signal levels are converted to 15 levels. While providing needed co-channel interference benefits, it is well-known that the (1-D) filter degrades white noise performance by $3 \mathrm{~dB}$. This is because the filter output is the subtraction of two full gain paths and, as white noise is uncorrelated from symbol to symbol, the noise power doubles. There is an additional $0.3 \mathrm{~dB}$ degradation due to error propagation introduced by precoding.

\section{APPROXIMATED ERROR PERFORMANCE ANALYSIS}

${ }^{1}$ This work was supported by LSI Logic Corp.

\author{
Robert H. Morelos-Zaragoza \\ SONY Computer Science Laboratories, Inc. \\ e-mail: morelosecsl.sony.co.jp
}

In the approximations presented in this section, we interpret the trellis code with decoding depth $k$, as a terminated zero-tail (ZT) $(3 k, 2 k-m)$ block code [3]. (For the four-state trellis decoder, $m=2$, while for 8 - and 16-state trellis decoders, $m=3$ and $m=4$, respectively.) When plotting the expressions with respect to the energy per bit-to-noise ratio $\left(E_{b} / N_{0}\right)$, a rate correction of $R_{L}(\mathrm{~dB})$ is applied, to account for the rate loss due to trellis termination, where $R_{L}=(2 k-m) / 2 k$. With the NTSC interference rejection filter in the receiver, the number of states in the decoder increases, due to a signal constellation of increased dimensionality. . In the guide to the ATSC system[2], a (1-D) filter is recommended that increases the number of signal levels from 8 of the original 8-PAM constellation to 15 at the output of the filter. To analyze the performance of the eight-state trellis decoder, a truncated union bound is computed using the technique of [3] as follows. A polynomial state transition matriz $\Pi 9 X$ ) for the 8-state trellis is used, with branch weights equal to $X^{d}$, where $d$ denotes the squared Euclidean distance (SED) with respect to the all-zero branch and $X$ is an indeterminant. For each set of three parallel branches between two states $i, j$, an element $\pi_{i, j}(X)$ in matrix $\Pi$ is a polynomial $\pi_{i, j}(X)=X^{d_{1}}+X^{d_{2}}+X^{d_{3}}$, where $d_{j}, j=1,2,3$, denotes the SED from the branch output to the all-zero sequence output. Using symbolic mathematical software, the value of the $k$-th power $\Pi^{k}(X)$ is computed and the coefficients of $\pi_{0,0}^{(k)}(X)$ yield the weight distribution of the ZT $(3 k,(2 k-3))$ block code. For the 8-state trellis decoder, with . $k=54, \pi_{0,0}^{(54)}(X)=5696 X^{56}+1520 X^{48}+404 X^{40}$ and for $16-$ state trellis decoder, $\pi_{0,0}^{(54)}(X)=840 X^{56}+248 X^{48}+101 X^{40}$. As shown above, the error coefficients for the MSED for the 16-state trellis decoder is much smaller than that of 8-state trellis decoder.

\section{Conclusion}

The simulation and approximated error performance shows that a TCM decoder with 16-states outperforms one with 8state by approximately $0.33 \mathrm{~dB}$ at a BER of $10^{-5}$. Finally, while the 8-state decoder must use a precoder for the uncoded bit to be able to decode properly, the proposed 16-state decoder does not and has a better error performance.

\section{REFERENCES}

[1] ATSC Standard A/53, ATSC Digital Television Standard, 1995.

[2] Guide to the Use of The ATSC Digital Television Standard A/54, ATSC Digital Television Standard, 1995.

[3] J. K. Wolf and A. J. Viterbi, "On the Weight Distribution of Linear Block Codes Formed from Convolutional Codes", IEEE Trans. Comm., vol. 44, no. 9, pp. 1049-1051, Sept. 1996. 